\author{
Military Technical College \\ Cairo, Egypt
}



\title{
EVALUATION OF LOCAL HUMPS AND A NEW HUMP DESIGN
}

\author{
$12^{\text {th }}$ International Conference \\ on Applied Mechanics and \\ Mechanical Engineering \\ (AMME)
} HUMP DESIGN

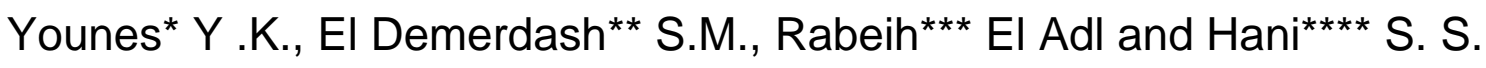

\begin{abstract}
The number of speed humps (sleeping policemen) in many countries has been increased steadily in the last decades. In this paper, the problem of installing nonspecified road humps in Cairo city has been studied. A simple measuring technique has been constructed to measure hump profiles at different zones in Cairo. Evaluation of the humps has been discussed based on the dynamic response of crossing vehicles. This evaluation shows that road humps are randomly installed depending on resident requirements which satisfy safety in their neighborhoods. Many of these humps may cause vehicle damages and driver discomfort; therefore, optimizing an ideal hump becomes one of the traffic control requirements. Optimized hump dimensions for a new hump shape is introduced. The extreme acceleration of the driver's seats of a truck and a passenger car is set as a multi objective function for the optimization process. The road-holding ability represented by the tire lift-off speed has been taken into consideration. The optimal calculations are based on Genetic Algorithm (GA) for its advanced searching ability. The results showed that, optimized humps are favorable than the current local and standard humps for both passenger cars and trucks.
\end{abstract}

\section{KEYWORDS}

Road humps, speed control, vehicle dynamics, vehicle suspension, global optimization, ride comfort, road-holding ability, ground clearance.

${ }^{\star}$ Professor, ${ }^{\star \star \star}$ Associate Prof, ${ }^{\star \star \star \star}$ Graduate Student, Mechanical Design Department

** Professor., Automotive Engineering Department

Helwan University - Faculty of Engineering - Mataria 


\section{NOMENCLATURE}

$\begin{array}{ll}a & \text { Fraction ratio } \\ b_{1}: b_{7} & \text { Vehicles dimensions } \\ C & \text { Damping matrix } \\ C_{s f}, C_{s r} & \text { Suspension dampers } \\ & \text { coefficients } \\ C_{t f}, C_{t r} & \text { Unspung masses damping } \\ F & \text { coefficients } \\ f & \text { Force vector } \\ h & \text { Objective function } \\ I & \text { Hump height } \\ I_{c} & \text { Body inertia } \\ K & \text { Cab inertia } \\ K_{s f}, K_{s r} & \text { Stiffness matrix } \\ & \text { Suspension Springs } \\ K_{t f}, K_{t r} & \text { Stiffnesses } \\ & \text { Unspung masses } \\ L & \text { Stiffnesses } \\ L_{r}, L_{f} & \text { Hump length } \\ L_{w} & \text { Ramp and flat lengths } \\ M & \text { Vehicle wheel base } \\ m_{b} & \text { Mass matrix } \\ m_{c} & \text { Body mass } \\ & \text { Cab mass }\end{array}$

\begin{tabular}{|c|c|}
\hline $\begin{array}{l}m_{w f}, m_{w r} \\
q_{i} \\
t\end{array}$ & $\begin{array}{l}\text { Unsprung masses } \\
\text { weighted parameters } \\
\text { Time }\end{array}$ \\
\hline$\theta_{b}, \dot{\theta}_{b}, \ddot{\theta}_{b}$ & $\begin{array}{l}\text { Body Pitch angle, velocity, } \\
\text { acceleration }\end{array}$ \\
\hline$\theta_{c}, \dot{\theta}_{c}, \ddot{\theta}_{c}$ & $\begin{array}{l}\text { Cab Pitch angle, velocity, } \\
\text { acceleration }\end{array}$ \\
\hline V & Vehicle velocity \\
\hline$X_{b f}, X_{b r}$ & $\begin{array}{l}\text { Front and rear body } \\
\text { displacement }\end{array}$ \\
\hline$X_{b}, \dot{x}_{b}, \ddot{x}_{b}$ & $\begin{array}{l}\text { Body vertical displacement, } \\
\text { velocity, acceleration }\end{array}$ \\
\hline$X_{c}, \ddot{x}_{c}, \ddot{x}_{c}$ & $\begin{array}{l}\text { Cab vertical displacement, } \\
\text { velocity, acceleration }\end{array}$ \\
\hline$X_{w f}, \dot{X}_{w f}, \ddot{X}_{w f}$ & $\begin{array}{l}\text { Front wheel displacement, } \\
\text { velocity, acceleration }\end{array}$ \\
\hline$x_{o f}$ & Front ground displacement \\
\hline$x_{\text {or }}$ & ar ground displacement \\
\hline$y_{0}$ & $\begin{array}{l}\text { Height of the hump profiling } \\
\text { equipment }\end{array}$ \\
\hline$y_{i}$ & $\begin{array}{l}\text { Length of the string at each } \\
\text { nodal point of the hump }\end{array}$ \\
\hline
\end{tabular}




\section{INTRODUCTION}

Road humps are one of the most efficient speed-reducing physical techniques. They give the driver clear physical feedback to encourage low speeds. If drivers increase the speed, then inconvenience increases drastically. Local humps are usually profiled in different streets taking into account the dynamic aspects of vehicles crossing these humps. Essen et al (1982), [1] stated sound criteria for speed humps; ideal hump should probably exhibit the following characteristics; (1) at and below the design speed, driver should be able to cross the hump without vehicle damage or loss of control and should not suffer discomfort, (2) above the design speed, the driver should suffer a degree of discomfort in terms of acceleration depending on the amount by which he violates the design speed. This acceleration should not exceed $0.6 \mathrm{~g}$ but it shouldn't lead to a vehicle damage or risk of loss of control (stability on the road). Unfortunately, the profile of current humps can not produce such ideal effects. For the above mentioned reasons, evaluating of local humps and optimizing an ideal hump becomes a satisfactory solution. The results of such optimized humps are compared to the standard sinusoidal profile hump $(3.7 \mathrm{~m}$ length and $7.5 \mathrm{~mm}$ height) which is considered as a favorable hump, [2].

The dimensions of suggested hump shapes are optimized using (GA). The objective is to make the ride pleasant as possible when crossing the hump below the maximum allowed speed, while being unpleasant when the vehicle goes too fast. Multi objective GA is used in this study to achieve the requirements for such ideal humps and to tackle a difficult design conflict between the ride quality and roadholding caused by road humps. Results have been obtained for five degrees of freedom car model and seven degrees of freedom truck model. 


\section{SYSTEM MODEL}

Fig. 1 and 2 show the passenger car, [2, 3] and the truck models, [4], respectively which are proposed in this work when crossing a hump. The following assumptions were employed when deriving the equations of motions; the unevenness of the road at the left and right tracks is the same. Furthermore, the vehicle is symmetric about the roll axis. The motion of the wheels is restricted to the vertical one only without considering the suspension geometry. The rear wheels follow the tracks of the front wheels. The time delay between the front and rear axles is considered in terms of vehicle wheelbase, $L_{w}$ and speed $V$.

The degrees of freedom of the car model are; vertical seat displacement, $x_{s c}$, vertical body displacement, $x_{b}$, vehicle body pitch angle, $\theta_{b}$, front and rear wheel displacements, $x_{w f}$ and $x_{w r}$, respectively.

The degrees of freedom of the truck model are; vertical seat displacement, $x_{s t}$, vertical cab displacement, $x_{c}$, cab pitch angle, $\theta_{c}$, vertical body displacement, $x_{b}$, vehicle body pitch angle, $\theta_{b}$, front and rear wheel displacements, $x_{w f}$ and $x_{w r}$, respectively.

The displacements are measured from the equilibrium position. The equations of motion are expressed in matrix form as follows:

$M \ddot{X}+C \dot{X}+K X=F$

Where $\mathrm{M}, \mathrm{C}$ and $\mathrm{K}$ are mass, damping and stiffness matrices respectively, they are defined in the appendix. $F$ and $X$ are the force and the displacement vectors respectively.

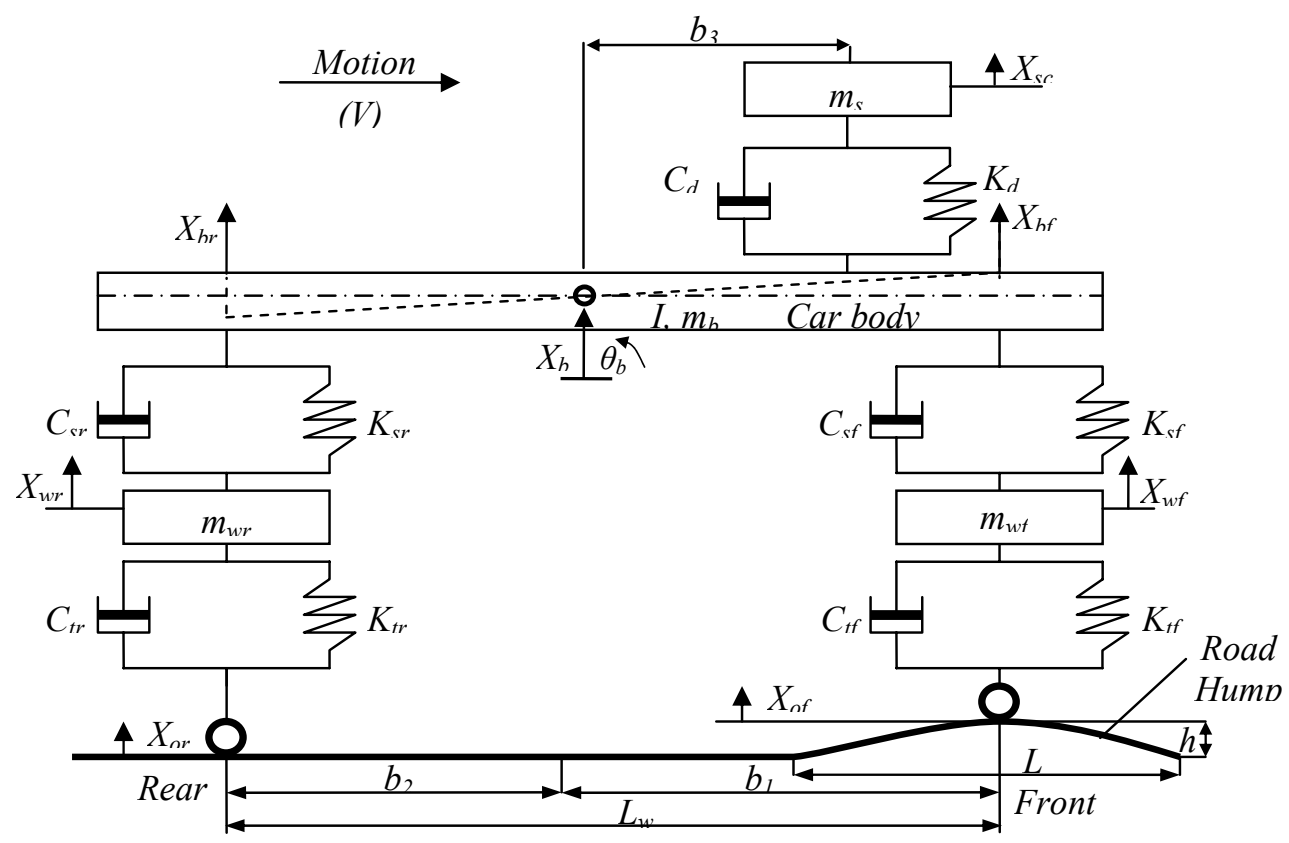

Fig.1. Five degrees of freedom-half car model, [3] 


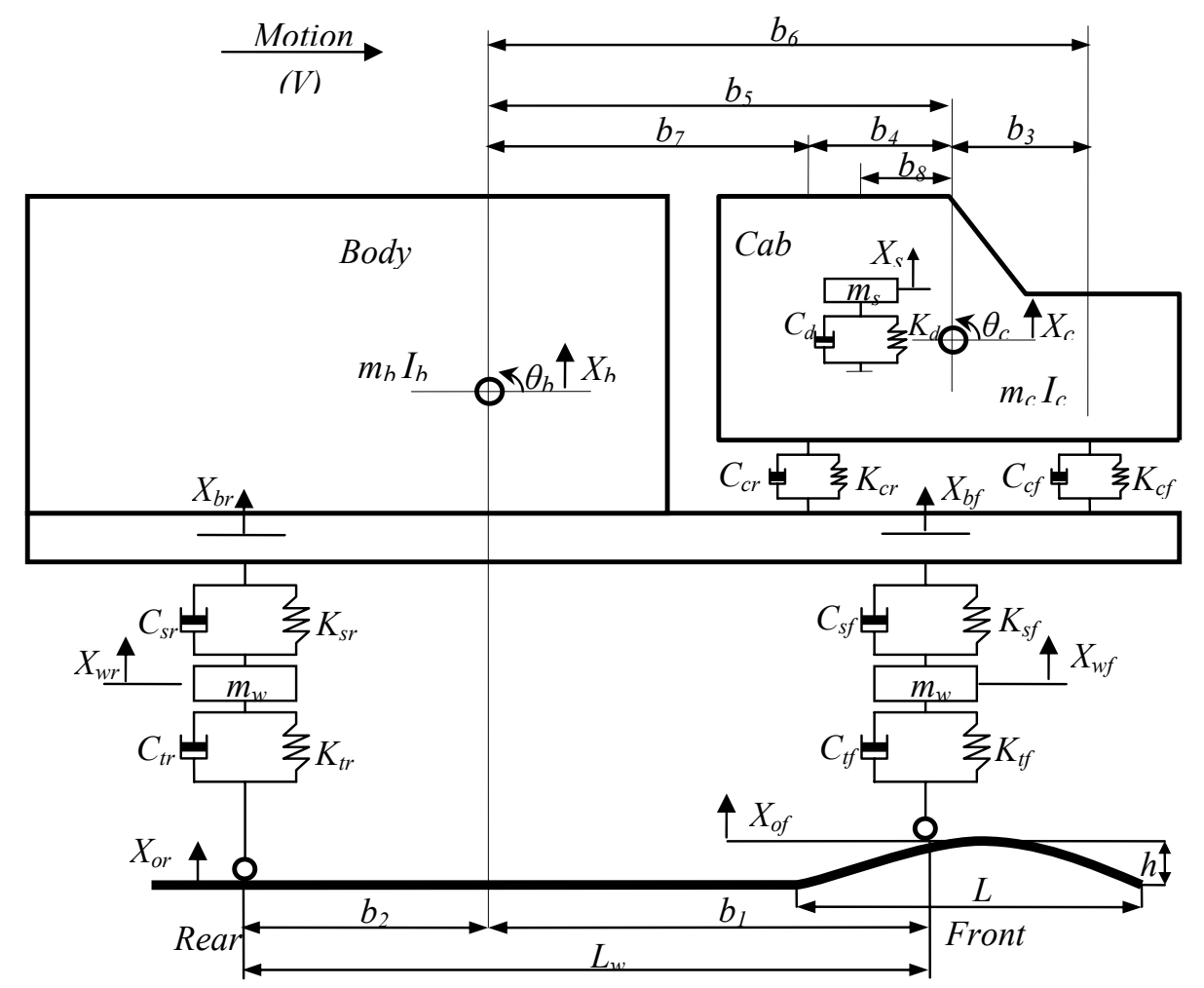

Fig.2. Seven degrees of freedom-half truck model, [4]

\section{PROFILES OF LOCAL HUMPS}

A simple equipment, Fig. 3, has been constructed to measure the shape of typical local humps installed in different streets in Cairo city.

The equipment is basically made of wooden beams. It consists of; horizontal beam with holes at equal spacing, (1), two vertical supports, (2), two flat bases, (3), bolts for fixation, (4) and string (5).

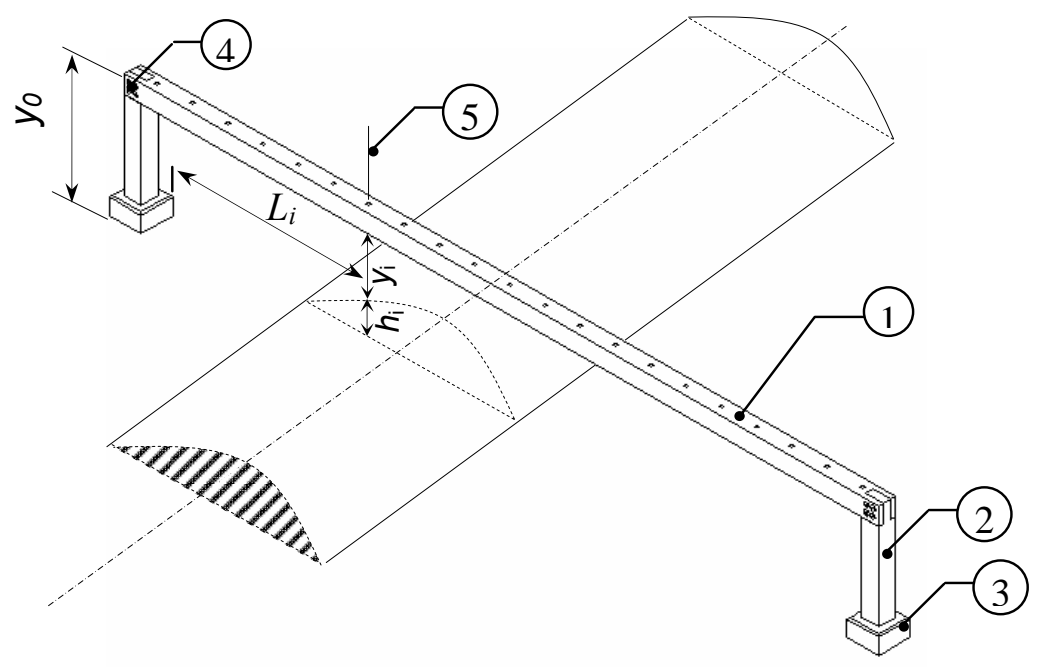

Fig.3. Assembly of the measuring equipment 
The equipment is positioned at the traveling direction of the road hump. The height of each hump nodal point " $h_{i}$ " is;

$\mathrm{h}_{\mathrm{i}}=\mathrm{y}_{0}-\mathrm{y}_{\mathrm{i}}, \quad \mathrm{i}=1: \mathrm{n}$

Profiles of six different humps have been measured at different zones in Cairo city, the data has been curve fitted as polynomials, Fig. 4


Fig.4. Measured and fitted humps profiles

\subsection{Performance of Vehicle dynamics}

The dynamic responses of a passenger car and a truck crossing the measured humps at different speeds have been investigated. Typical data of a passenger car and a truck taken from the previous work, [2], have been used to perform the calculations. The performance of vehicle dynamics is commonly assessed in four parameters; Ride Comfort (RC), Suspension Working Space (SWS), Total Tire Load (TTL), and Dynamic Ground Clearance (DGC).

\subsubsection{Ride dynamics of the passenger car}

The dynamic parameters of a passenger car crossing the different humps are shown in Fig.6. In terms of the ride comfort, Fig. $6 \mathrm{a}$ and $6 \mathrm{~b}$ show that hump $A$ is considered as the most favorable hump, giving less $\ddot{x}_{b}$ ) $\max$ and $\ddot{\theta}_{b}$ ) max values especially at low speeds. The other humps have undesirable effects and will disturb the passengers 
due to their high vertical and pitch acceleration with car speeds specially humps "D" and "E".

Fig. $6 \mathrm{c}$ and $6 \mathrm{~d}$ show that the hump "A" gives relatively less suspension deflection, whereas it is considerably higher for both humps "D" and "E".

The car wheel will leave the road if the car exceeded the maximum speed (lift-off speed), shown in the Table 1. Hump "A" is the safest one due to its high tire lift-off speed, while hump "F" needs the car to come to a near stop before passing the hump safely. Fig. 6e and $6 f$ show the total tire load against the vehicle speed.

Table 1. Maximum speed limits of the car crossing local humps

\begin{tabular}{|l|c|c|c|c|c|c||}
\hline Hump & A & B & C & D & E & F \\
\hline Speed Limits (km/hr) & 69 & 36 & 32 & 34 & 14 & 6 \\
\hline
\end{tabular}
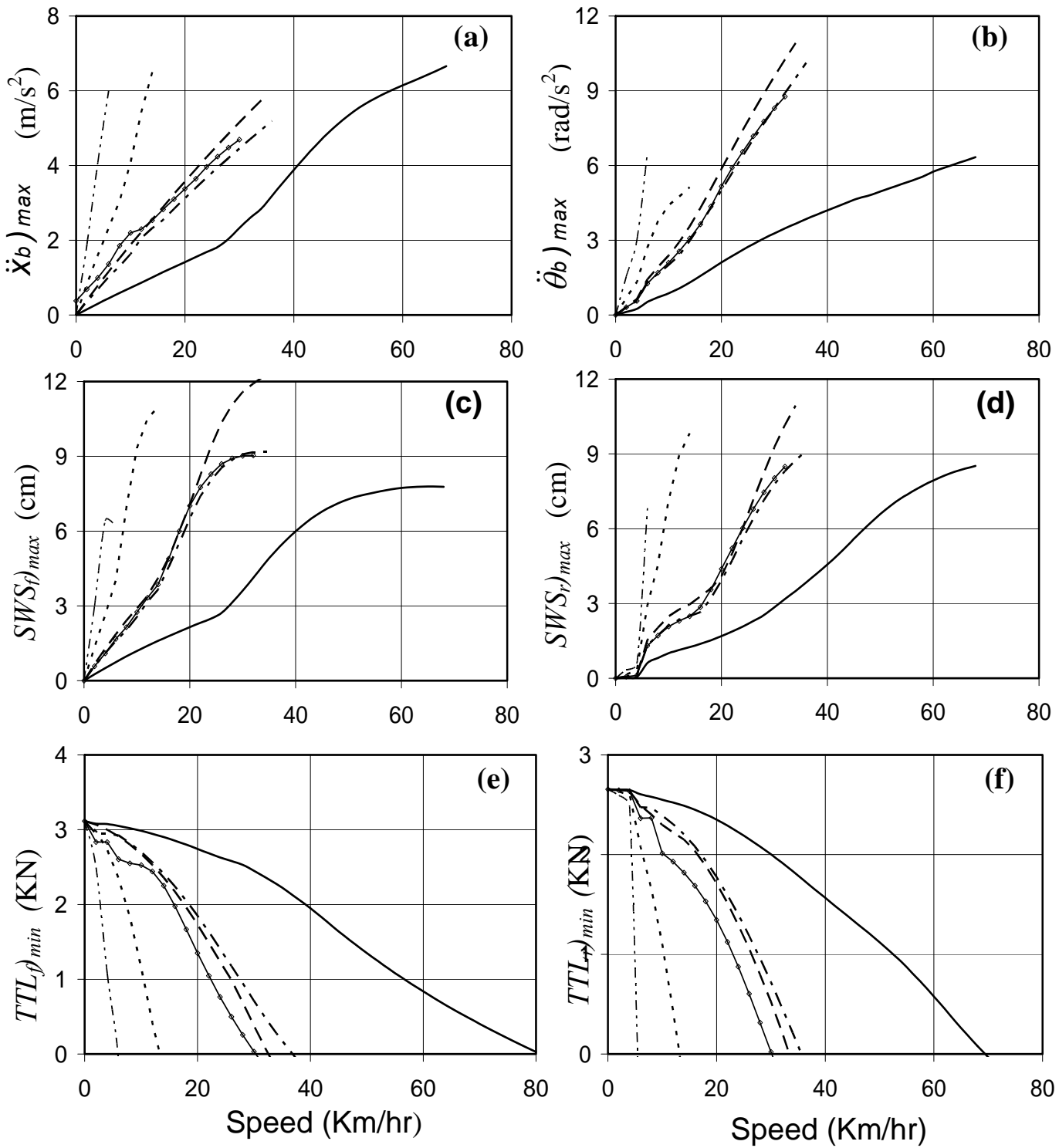

- A - - B $\rightarrow \mathrm{C}--\mathrm{D}$

E $\quad-\cdots-\mathrm{F}$

Fig.6. Dynamic performance parameters of the car crossing different humps 


\subsubsection{Ground clearance}

The ground clearance has to be checked to avoid hitting the undercarriage at relatively high speeds. Examining the undercarriage of the car crossing the humps at different speeds, it is found that humps "E" and "F" are considered dangerous, due to their short length and long height. The car critical speed $\left(V_{c r}\right)$ for each hump can be calculated as:

$V_{c r}=\frac{\omega L}{\pi}$

where $\omega$ is the first natural frequency of the car and $L$ is the hump length.

The critical speeds for crossing humps "D" and "E" are calculated using the above equation wit $\mathrm{V}=13.15 \mathrm{~km} / \mathrm{hr}$ and $5.07 \mathrm{~km} / \mathrm{hr}$ respectively.

As shown in Fig. $7 \mathrm{a}$, when the car passes over hump "D" at a speed equal to 13.32 $\mathrm{km} / \mathrm{hr}$, or over, the undercarriage is still in the safe position and it doesn't hit the hump, while, as shown in Fig. 7b, when the car crosses the hump "E" at a speed of $5.14 \mathrm{~km} / \mathrm{hr}$, or over, the bottom of the car will hit the top of the hump. In this case even if the driver reduces the speed and follows the regulation, his car will be damaged.
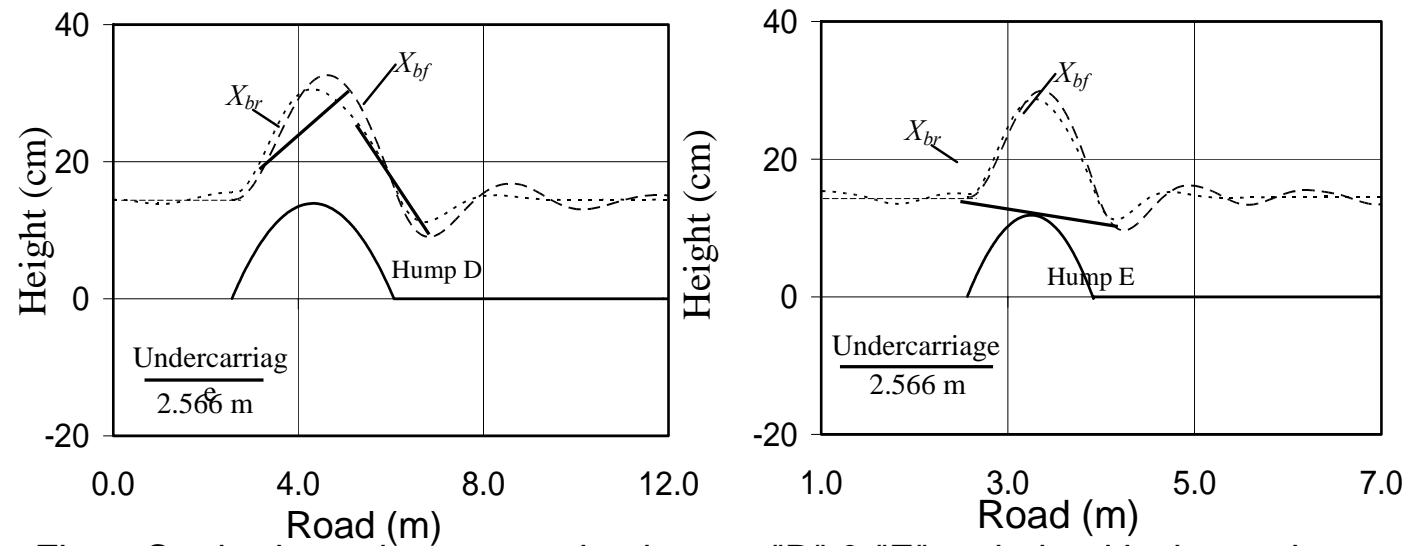

Fig.7. Car body motion at crossing humps "D" \& "E" at their critical speeds

\subsubsection{Ride dynamics of a truck}

Similar investigations have been carried out for a truck model. The obtained results are shown in Fig. 8. Figures $8 \mathrm{a}$ and $8 \mathrm{~b}$ show the ride comfort represented by the maximum vertical acceleration $\left.\ddot{x}_{c}\right)_{\max }$ and pitch acceleration $\ddot{\theta}_{c}$ ) max of the cab. Hump " $A$ " provides better comfort throughout a wide range of truck speeds. The rest humps, especially "D" and "E", give more discomfort feelings. As for the passenger car, the hump " $A$ " is a better proposition for its minimum effects on truck suspension deflections, Fig. 8c and Fig. 8d. The tire lift-off speed limits are shown in Table 2. and figures $8 \mathrm{e}$ and $8 \mathrm{f}$. It is clear that, hump "A" provides more safety, but is still less safe than the standard humps, while the other humps needs very slow speeds for trucks to pass safely without loosing contact with the road, specially for humps ' $E$ " and " $F$ ".

Table 2. Maximum speed limits of the truck crossing local humps shapes

\begin{tabular}{|l|c|c|c|c|c|c||}
\hline Hump & A & B & C & D & E & F \\
\hline Speed Limits (km/hr) & 55 & 25 & 25 & 24 & 10 & 7 \\
\hline
\end{tabular}

Due to the high ground clearance of the truck all humps do not cause the problem of hitting the bottom of the truck and it can pass safely. 


\section{MODEL PROFILE OPTIMIZATION}

The parameters used in this study to describe the level of comfort, are the maximum vertical acceleration of the passenger car seat, $\left.\ddot{x}_{s c}\right)_{\max }$, and the maximum vertical acceleration of the truck seat, $\left.\ddot{x}_{s t}\right)_{\max }$. GA is used to get a new hump shape for optimal comfort;
$\left.\ddot{X}_{s c}\right)_{\max }=\operatorname{Max}\left(\ddot{X}_{s c}\right)$
$t\left[t_{\text {start }}: t_{\text {end }}\right]$
$\left.\ddot{x}_{s t}\right)_{\max }=\operatorname{Max}\left(\ddot{x}_{s t}\right)$
$\mathrm{t}\left[\mathrm{t}_{\text {start }}: t_{\text {end }}\right]$

The objective function is given by;
$\left.\left.\left.\left.\left.\left.f=\mathrm{q}_{1}\left(\ddot{x}_{s c}\right)_{\text {desired }}-\ddot{X}_{s c}\right)_{\max }\right)_{R M S}\right]_{\mathrm{v}=30}^{\mathrm{v}=0}+\mathrm{q}_{2}\left(\ddot{x}_{s t}\right)_{\text {desired }}-\ddot{X}_{s t}\right)_{\max }\right)_{R M S}\right]_{\mathrm{v}=30}^{\mathrm{v}=0}$
$\left.\left.\left.\left.\left.\left.+\mathrm{q}_{3}\left(\ddot{x}_{s c}\right)_{\text {desired }}-\ddot{X}_{s c}\right)_{\max }\right)_{R M S}\right]_{\mathrm{v}=100}^{\mathrm{v}=30}+\mathrm{q}_{4}\left(\ddot{x}_{s t}\right)_{\text {desired }}-\ddot{X}_{s t}\right)_{\max }\right)_{R M S}\right]_{\mathrm{v}=100}^{\mathrm{v}=30}$ where

$\left.\ddot{X}_{s c}\right)_{\max }$ Maximum vertical acceleration of the passenger car's seat, $\left(\mathrm{m} / \mathrm{s}^{2}\right)$.

$\left.\ddot{X}_{s t}\right)_{\max } \quad$ Maximum vertical acceleration of the truck's seat, $\left(\mathrm{m} / \mathrm{s}^{2}\right)$.

q1:q4 Weighting constants used to optimize the relative importance of the objective function terms.

$\left.\ddot{x}_{s c, s t}\right)_{\text {desired }}$ Desired seat vertical acceleration. Its value is zero $\mathrm{m} / \mathrm{s}^{2}$ below the allowable speed of the hump which is taken equal to $30 \mathrm{~km} / \mathrm{hr}$ while it is $0.6 \mathrm{~g}$ above this speed [1].
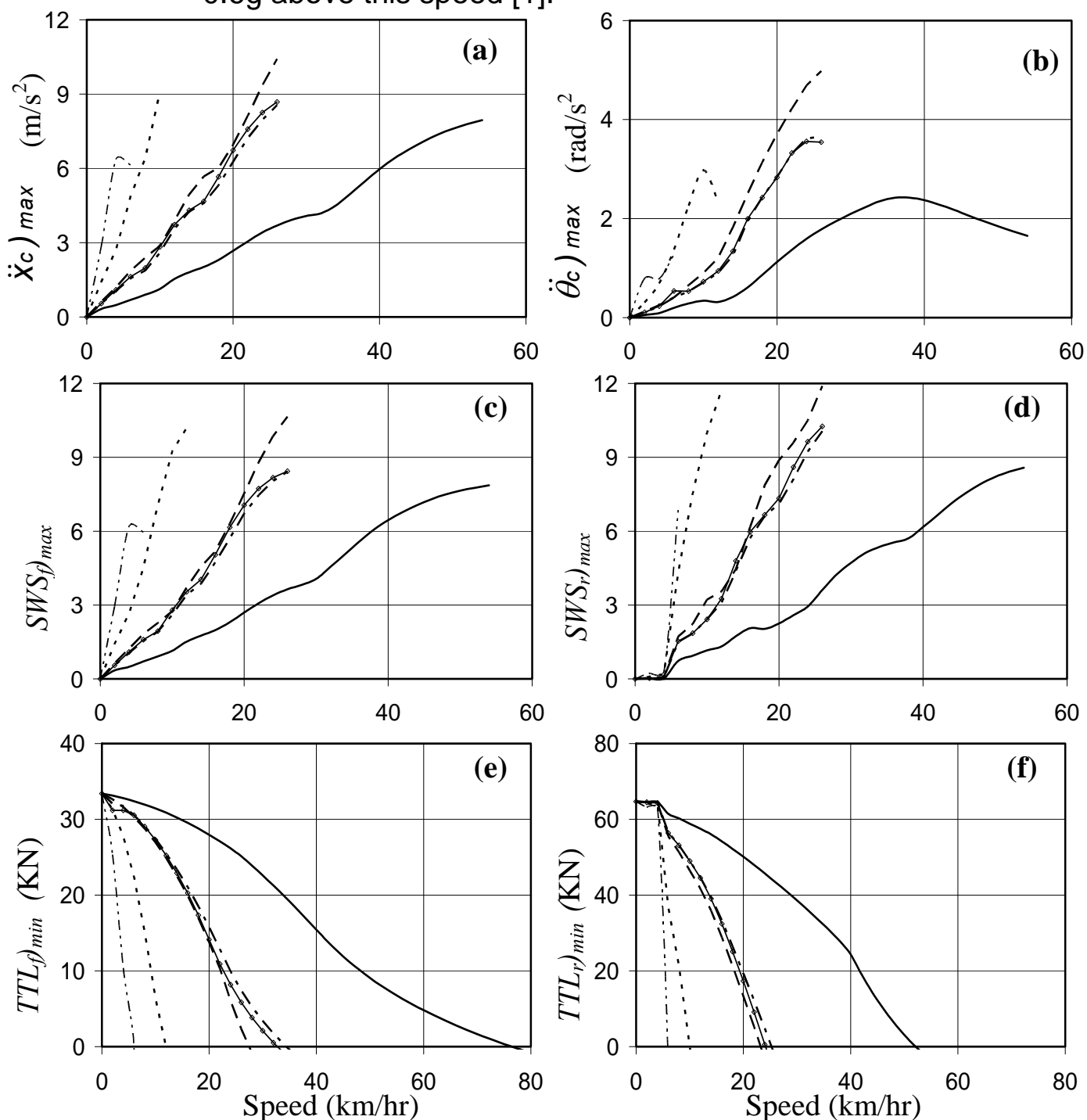

Fig.8. Effect of truck speed on the dynamic performance parameters 
Table 3. Genetic algorithm parameters.

\begin{tabular}{|c|c|c|}
\hline Parameter & Symbol & Value \\
\hline \hline Number of individuals & NIND & 30 \\
\hline Maximum number of generation & MAXGEN & 1000 \\
\hline Generation gap & GGAP & 0.9 \\
\hline Precision of binary representation & PRECI & 24 \\
\hline Accuracy & ACC & $1 \mathrm{e}-20$ \\
\hline
\end{tabular}

In GA calculations, 30 individuals are selected as the population size for one generation. The maximum number of generation is 1000 which is considered enough to reach the desired accuracy. At each generation the first $90 \%$ of the individuals are selected according to their level of fitness and are bred together to create the new generation. Twenty four bits of binary numbers are chosen for each individual and are equally divided into parts of the number of the optimized coefficients. The program terminates when the accuracy reaches to $1 \mathrm{e}-20$ or the generations reach 1000.

\section{NEW HUMP SHAPE}

The shape of the proposed hump is described by a summation of harmonics which are represented by the Fourier series. The general form of Fourier series is given by:

$$
\mathrm{f}(\mathrm{x})=\mathrm{a}_{0}+\sum_{\mathrm{n}=1}^{\infty}\left(\mathrm{b}_{\mathrm{n}} \cos \mathrm{n} \mathrm{x}+\mathrm{a}_{\mathrm{n}} \sin \mathrm{nx}\right)
$$

The hump begins and ends with zero height, thus the terms $b_{0}$ and the cosine terms can be ignored and the Fourier equation can be simplified to.

$$
f(x)=\sum_{n-1}^{\infty}\left(a_{n} \sin n x\right)
$$

Where $\mathrm{n}$ is the number of Fourier terms.

For trial processes choosing $n=10$ terms, the last amplitudes give a fraction of millimeters, which is relatively small compared to the first five terms. Thus five terms are considered for expressing the Fourier function to define the humps. Since the hump profile represents the excitation function of the vehicle crossing the hump, the excitation equation is;

$$
f(x)=\sum_{n-1}^{5}\left(a_{n} \sin \left(\frac{n \cdot \pi \cdot V}{L} \cdot t\right)\right)
$$

The optimized parameters are $a_{1}, a_{2}, a_{3}, a_{4}, a_{5}$, and the hump length $L$, In addition to the parameters in Table 3 , the genetic parameters and their boundaries shown in

\begin{tabular}{|c|c|}
\hline Number of variables (NVAR) & 6 \\
\hline Lower boundaries $(L B)$ of $\left[a_{1}: a_{5}, L\right](\mathrm{m})$ & 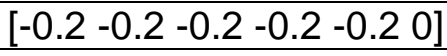 \\
\hline Upper boundaries (UB) of $\left[a_{1}: a_{5}, L\right](\mathrm{m})$ & {$\left[\begin{array}{llllll}0.2 & 0.2 & 0.2 & 0.2 & 0.2 & 6\end{array}\right]$} \\
\hline
\end{tabular}
table (4) are applied.

Table 4. Optimized parameters and their boundaries 


\section{RESULTS AND DISCUSSION}

Three cases of weighted coefficients (q's), shown in the Table 5, are considered. The results of the genetic optimization of the new hump shape are summarized in Table 5 and compared with the standard sinusoidal profile hump shown in the Fig. 10.

Table 5. Genetic algorithm results for new hump shape.

\begin{tabular}{|c|c|c|c|}
\hline Optimized parameters & $\begin{array}{c}\text { Case I } \\
q^{\prime} s=\left[\begin{array}{llll}1 & 1 & 1 & 1\end{array}\right]\end{array}$ & $\begin{array}{c}\text { Case II } \\
\text { q's=[2 } 12 \\
1]\end{array}$ & $\begin{array}{c}\text { Case III } \\
\text { q's=[3.5 } 3.51 \\
1]\end{array}$ \\
\hline$a_{1}(\mathrm{~cm})$ & 9.81 & 9.05 & 6.91 \\
\hline$a_{2}(\mathrm{~cm})$ & 0.21 & 0.62 & 0.31 \\
\hline$a_{3}(\mathrm{~cm})$ & 0.26 & 0.12 & 0.08 \\
\hline$a_{4}(\mathrm{~cm})$ & 0.09 & 0.33 & 0.23 \\
\hline$a_{5}(\mathrm{~cm})$ & 0.01 & 0.02 & -0.02 \\
\hline Hump Length $L(m)$ & 5.93 & 5.97 & 5.99 \\
\hline Car's Speed Limit (km/hr) & 58 & 51 & 83 \\
\hline $\begin{array}{c}\text { Truck's Speed Limit } \\
\text { (km/hr) }\end{array}$ & 52 & 51 & 101 \\
\hline
\end{tabular}

In case I, the weighted coefficients are equal although it gives desirable results. the tire lift-off speeds are low for the passenger car and the truck. Changing the weighting factors as in the case II, gives a better improvement in the tire lift-off speeds. In case III, the weighted coefficients are chosen so that the acceleration at the driver's seats is less than the standard one below the allowable speed of 30 $\mathrm{km} / \mathrm{hr}$. It is higher above this speed. In addition, the tire lift-off speed is much higher than that of the standard humps and which increases the vehicles safety.

From Table 5 and Fig. 10, all cases provide better performance than the standard sinusoidal profile hump in terms ride comfort increase, below the allowable speed, but not all cases provide a better vehicle stability.


Fig.10. New shape optimized hump for passenger car and truck performance compared to the standard sinusoidal hump 


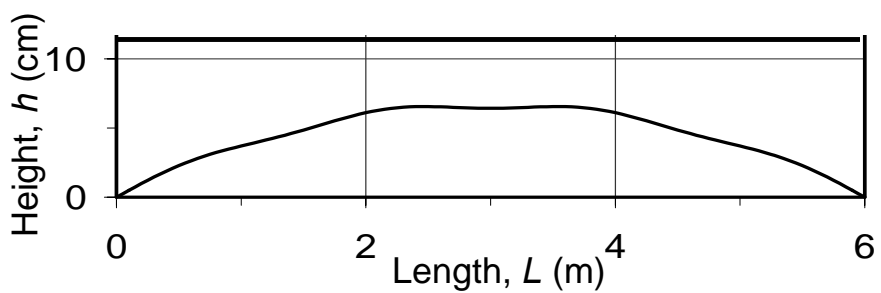

Fig.11. A new proposed hump shape profile.

Fig. 11 shows the shape of the proposed hump profile which satisfies the desired hump characteristics. The proposed hump is 6 meter wide and $6.6 \mathrm{~cm}$ high.

\section{CONCLUSIONS}

This paper has described a new proposed hump which may be used to control the traffic instead of both local and standard humps. The response characteristics of two different vehicles crossing a speed hump can be optimized using genetic algorithms several conclusions may be deduced:

1- The evaluation of local humps reveals that no standard profiles or dimensions are used in Cairo streets.

2- Some of the local humps either their height is too high or they are too short in length, producing discomfort feelings and are not safe for vehicles specially the passenger cars with small ground clearance.

3- All optimized humps are more favorable than the standard humps for both passenger car and truck.

4- The safety of the vehicles and passengers has been kept high, no matter the driver exceeds the limit speed or not, as the tire lift-off speed is much higher than the standard humps. In the same time, the driver may suffer feelings of uncomfort when crossing the hump at high speeds.

5- The functions used to describe the new shape are used because they can describe a large variety of shapes with only few parameters.

6- Most of the optimized humps lengths are between 5.7 and 6 meter and their heights are between 6.54 and 8.03 centimeters depending on the hump shape.

\section{REFERENCES}

[1] Essen, K. and Al-Nassar, Y. "Dynamic Considerations of Speed Control Humps" J. of Transport Research, Vol. I6B, No. 4, pp. 291-302, 1982.

[2] Hani, S., "Effect of Speed Control Humps on Vehicle Dynamics" MSc. Thesis, Faculty of Engineering-Matria, Helwan University, 2005.

[3] Gabriele, F., "Vertical Dynamics of Vehicles and Perception Quantities" Diploma Thesis, Institute of Mechanics \& Mechanisms, Sweden, 2001.

[4] El Demerdash, S. , "Improvement of Trucks Ride Dynamics Using A Hydraulic Semi-Active Suspension System" SAE, 2002013039, 2002. 


\section{APPENDIX}

The passenger car-hump system matrices are;

$$
\begin{aligned}
& M=\left[\begin{array}{ccccc}
m_{s} & 0 & 0 & 0 & 0 \\
0 & m_{b} & 0 & 0 & 0 \\
0 & 0 & I & 0 & 0 \\
0 & 0 & 0 & m_{w f} & 0 \\
0 & 0 & 0 & 0 & m_{w r}
\end{array}\right]
\end{aligned}
$$

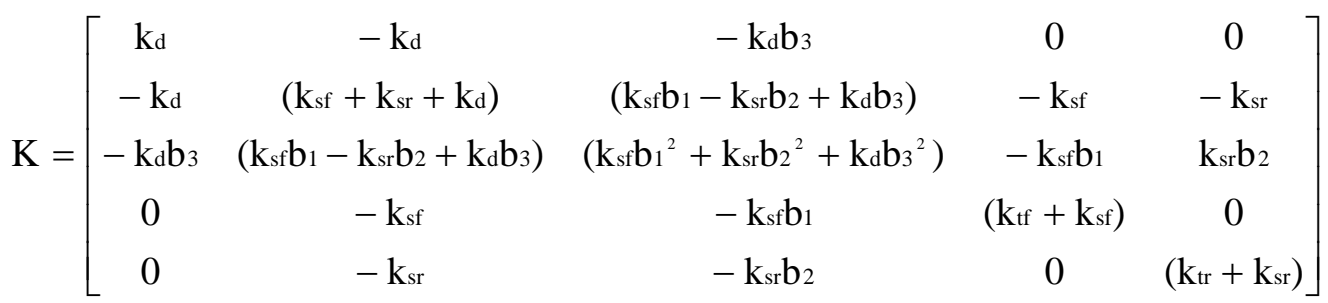



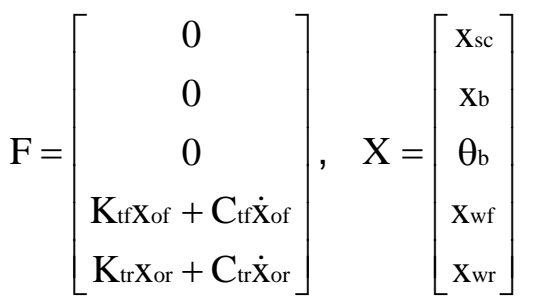

The truck -hump system matrices are:

$$
\mathrm{M}=\left[\begin{array}{ccccccc}
\mathrm{m}_{\mathrm{s}} & 0 & 0 & 0 & 0 & 0 & 0 \\
0 & \mathrm{~m}_{\mathrm{c}} & 0 & 0 & 0 & 0 & 0 \\
0 & 0 & \mathrm{I}_{\mathrm{c}} & 0 & 0 & 0 & 0 \\
0 & 0 & 0 & \mathrm{~m}_{\mathrm{b}} & 0 & 0 & 0 \\
0 & 0 & 0 & 0 & \mathrm{I}_{\mathrm{b}} & 0 & 0 \\
0 & 0 & 0 & 0 & 0 & \mathrm{~m}_{\mathrm{wf}} & 0 \\
0 & 0 & 0 & 0 & 0 & 0 & \mathrm{~m}_{\mathrm{wr}}
\end{array}\right]
$$


$\mathrm{K}=\left[\begin{array}{ccccccc}\mathrm{kd}_{\mathrm{d}} & -\mathrm{kd}_{\mathrm{d}} & -\mathrm{k}_{\mathrm{d}} \mathrm{b}_{8} & 0 & 0 & 0 & 0 \\ -\mathrm{kd}_{\mathrm{d}} & \mathrm{s}_{1} & \mathrm{~s}_{2} & \mathrm{~s}_{3} & \mathrm{~s}_{4} & 0 & 0 \\ -\mathrm{kd}_{8} \mathrm{~b}_{8} & \mathrm{~S}_{2} & \mathrm{~S}_{5} & \mathrm{~S}_{6} & \mathrm{~s}_{7} & 0 & 0 \\ 0 & \mathrm{~S}_{3} & \mathrm{~S}_{6} & \mathrm{~S}_{8} & \mathrm{~S}_{9} & -\mathrm{k}_{\mathrm{sf}} & -\mathrm{k}_{\mathrm{sr}} \\ 0 & \mathrm{~S}_{4} & \mathrm{~S}_{7} & \mathrm{~S}_{9} & \mathrm{~S}_{10} & \mathrm{k}_{\mathrm{sf}} \mathrm{b}_{1} & -\mathrm{k}_{\mathrm{sr}} \mathrm{b}_{2} \\ 0 & 0 & 0 & -\mathrm{k}_{\mathrm{sf}} & \mathrm{k}_{\mathrm{sf}} \mathrm{b}_{1} & \mathrm{~s}_{11} & 0 \\ 0 & 0 & 0 & -\mathrm{k}_{\mathrm{sr}} & -\mathrm{k}_{\mathrm{sf}} \mathrm{b}_{1} & 0 & \mathrm{~S}_{12}\end{array}\right]$

$\mathrm{C}=\left[\begin{array}{ccccccc}\mathrm{Cd} & -\mathrm{Cd}_{1} & -\mathrm{Cdb}_{8} & 0 & 0 & 0 & 0 \\ -\mathrm{Cd}_{1} & \mathrm{~d}_{1} & \mathrm{~d}_{2} & \mathrm{~d}_{3} & \mathrm{~d}_{4} & 0 & 0 \\ -\mathrm{Cd}_{8} & \mathrm{~d}_{2} & \mathrm{~d}_{5} & \mathrm{~d}_{6} & \mathrm{~d}_{7} & 0 & 0 \\ 0 & \mathrm{~d}_{3} & \mathrm{~d}_{6} & \mathrm{~d}_{8} & \mathrm{~d}_{9} & -\mathrm{Csf}_{\mathrm{sf}} & -\mathrm{Csr} \\ 0 & \mathrm{~d}_{4} & \mathrm{~d}_{7} & \mathrm{~d}_{9} & \mathrm{~d}_{10} & \mathrm{Cs}_{1} & -\mathrm{Csr}_{2} \\ 0 & 0 & 0 & -\mathrm{Csf}_{2} & \mathrm{Css}_{1} & \mathrm{~d}_{11} & 0 \\ 0 & 0 & 0 & -\mathrm{Csr}_{1} & -\mathrm{Css}_{1} \mathrm{~b}_{1} & 0 & \mathrm{~d}_{12}\end{array}\right]$

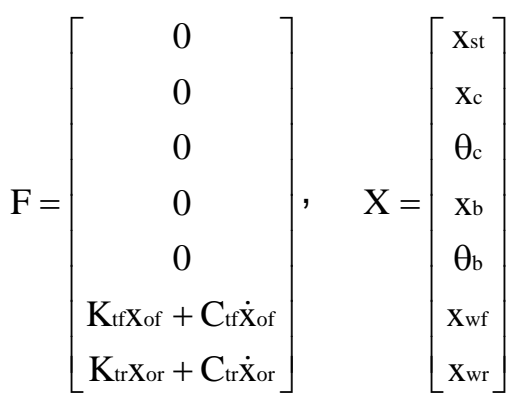

Where

$d_{1}=\left(C_{c f}+C_{c r}\right)$

$d_{2}=\left(b_{4} C_{c r}-b_{3} C_{c f}\right)$

$d_{3}=-\left(C_{c f}+C_{c r}\right)$

$d_{4}=\left(b_{7} C_{c r}+b_{6} C_{c f}\right)$

$d_{5}=\left(b_{3}{ }^{2} C_{c f}+b_{4}{ }^{2} C_{c r}\right)$

$d_{6}=\left(b_{3} C_{c r}-b_{4} C_{c r}\right)$

$d_{7}=\left(b_{4} b_{7} C_{c r}-b_{3} b_{6} C_{c f}\right)$

$d_{8}=\left(C_{s f}+C_{s r}+C_{c f}+C_{c r}\right)$

$d_{9}=\left(-b_{1} C_{s f}+b_{2} C_{s r}-b_{6} C_{c f}-b_{7} C_{c r}\right)$

$d_{10}=\left(b_{1}^{2} C_{s f}+b_{2}^{2} C_{s r}+b_{6}^{2} C_{c f}+b_{7}^{2} C_{c r}\right)$

$d_{11}=\left(C_{s f}+C_{t f}\right)$

$d_{12}=\left(C_{s r}+C_{t r}\right)$

$s_{1}=\left(K_{c f}+K_{c r}\right)$

$s_{2}=\left(b_{4} K_{c r}-b_{3} K_{c f}\right)$

$s_{3}=-\left(K_{c f}+K_{c r}\right)$

$s_{4}=\left(b_{7} K_{c r}+b_{6} K_{c f}\right)$

$s_{5}=\left(b_{3}{ }^{2} K_{c f}+b_{4}{ }^{2} K_{c r}\right)$

$s_{6}=\left(b_{3} K_{c r}-b_{4} K_{c r}\right)$

$s_{7}=\left(b_{4} b_{7} K_{c r}-b_{3} b_{6} K_{c f}\right)$

$s_{8}=\left(K_{s f}+K_{s r}+K_{c f}+K_{c r}\right)$

$s_{9}=\left(-b_{1} K_{s f}+b_{2} K_{s r}-b_{6} K_{c f}-b_{7} K_{c r}\right)$

$s_{10}=\left(b_{1}^{2} K_{s r}+b_{2}^{2} K_{s r}+b_{6}^{2} K_{c f}+b_{7}^{2} K_{c r}\right)$

$s_{11}=\left(K_{s f}+K_{t t}\right)$

$s_{12}=\left(K_{s r}+K_{t r}\right)$ 